\title{
The Role of the Intestinal Mucosa in Iron Absorption*
}

\author{
R. W. Charlton, P. Jacobs, J. D. Torrance, and T. H. Bothwell \\ (From the Council for Scientific and Industrial Research Iron and Red Cell Metabolism Unit, \\ Department of Medicine, University of the Witwatersrand Medical School, \\ Johannesburg, South Africa)
}

External iron exchange is normally very limited in proportion to the body iron content of between 3 and $4 \mathrm{~g}$ (2). In the adult male the total loss from exfoliated cells and secretions is between 0.5 and $1.0 \mathrm{mg}$ daily. These losses are matched by the absorption of iron from food, so that the total iron content of the body tends to remain fixed within relatively narrow limits. Although there is some evidence that losses are influenced by the total body content, such variations in excretion seem to be fixed within fairly narrow limits, so that normal iron balance is primarily dependent on the behavior of the absorbing cells of the upper gastrointestinal tract. Thus the absorption rate tends to rise when the body is depleted of iron and to fall when stores are larger than normal. The manner in which this control is effected is, however, less certain. Originally Granick suggested that the amount of iron absorbed at any one time was influenced by the ferritin content of the absorbing cells (3). However, some doubt was subsequently cast on this theory since ferritin, although demonstrable in gut cells after the feeding of very large doses of iron (3-5), could not be shown to be present after small quantities (6-8). Recently Crosby and co-workers reinvestigated the problem and, on the basis of their findings, proposed that only a proportion of the iron taken up by the gut reaches the plasma (911). The remainder is held within mucosal cells and is subsequently lost into the lumen of the bowel when the cells exfoliate. Although these workers did not positively identify the nature of

* Submitted for publication August 14, 1964 ; accepted December 3, 1964.

These studies were supported in part by a grant (AM 04912-03) from the National Institutes of Health, Bethesda, Md., and in part by grants from the Council for Scientific and Industrial Research and the Atomic Energy Board, South Africa. A preliminary report of some of these data has been published previously (1). this stored iron, they produced electron microscopic evidence suggesting it might be ferritin (12). In similar studies carried out in our laboratory further evidence has been obtained on some of the mechanisms involved in iron absorption and on the role of ferritin in this process. The results of these investigations, some of which have been published previously in preliminary form $(1)$, are reported in full in the present communication.

\section{Methods}

Adult rats of the Wistar strain weighing between 150 and $250 \mathrm{~g}$ were studied, matched animals being used in each experiment. When iron-overloaded rats were required, 10 intramuscular injections of $1 \mathrm{mg}$ iron as ironsorbitol-citrate (Jectofer ${ }^{1}$ ) were given on successive days. Iron-deficient animals were obtained by raising weanlings on a semisynthetic diet of low iron content (13). In some studies 2 to $3 \mathrm{ml}$ blood was removed by cardiac puncture on days 4 and 2 before use. All animals were starved for 24 hours before absorption studies. Iron as ferric chloride, labeled with $\mathrm{Fe}^{50}$, was dissolved in $1 \mathrm{ml}$ distilled water and administered via esophageal cannula. In some experiments the animals were killed at various intervals after administration of the iron, and the whole gastrointestinal tract was removed intact. Absorption was then assessed by counting the remainder of the carcass in a whole body counter consisting of a ring of matched Geiger-Müller tubes. In other experiments the whole animal was counted 7 days after the administration of the isotope. When the uptake of iron into mucosal cells was studied, the intestine was washed before homogenization. In some experiments a $10-\mathrm{cm}$ length of intestine from the pylorus distally was perfused for 1 minute with 10 to $20 \mathrm{ml} 0.9 \% \mathrm{NaCl}$ solution or $0.01 \mathrm{M}$ EDTA ( $\mathrm{pH} \mathrm{7.0)}$ in $0.9 \% \mathrm{NaCl}$ solution, at a pressure of $60 \mathrm{~cm}$ water. In experiments in which uptake into the whole small intestine was determined, the bowel was opened longitudinally and rinsed for half a minute in each of two beakers containing $20 \mathrm{ml} 0.9 \%$

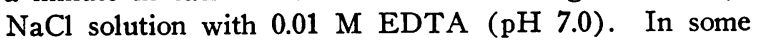
experiments mucosa was freed from the intestine before homogenization by compression with the edge of a glass slide. Pushing the slide towards the cut end of the

1 Obtained from Astra, Södertälje, Sweden. 
bowel resulted in the "milking" of mucosa from the muscular layers. The extruded mucosa was then washed by shaking in a test tube with either $0.9 \% \mathrm{NaCl}$ or $0.01 \mathrm{M}$ EDTA ( $\mathrm{pH} \mathrm{7.0)}$ in $0.9 \% \mathrm{NaCl}$, centrifuging, and discarding the supernate. After washing, the intestine or the mucosa was homogenized either in water or in $0.1 \mathrm{M}$ EDTA ( $\mathrm{pH} \mathrm{7.0)}$ in water. Uptake of the labeled iron into intestinal cells was assessed by counting samples of the homogenate in a well type scintillation counter or by counting the whole washed intestine in the whole body counter.

Identification of ferritin. Several $\mathrm{ml} 0.1 \mathrm{M}$ EDTA ( $\mathrm{pH}$ 7.0) was added to washed gut, and the mixture was homogenized and then heated to $70^{\circ} \mathrm{C}$ over a period of 5 minutes. After centrifugation at $9,000 \times g$ for 10 minutes, the supernatant solution was collected. Alum-precipitated horse spleen ferritin was isolated by the method of Mazur and Shorr (14), and antiserum was prepared by bleeding rabbits immunized with samples of this ferritin using a modification of the method of Proom (15). [The cross-specificity of horse spleen ferritin and rat liver ferritin has been established (16)]. One $\mathrm{ml}$ of the pooled antiserum precipitated approximately $1 \mathrm{mg}$ ferritin. To a sample of the mucosal supernatant solution to be tested was added $1 \mathrm{ml}$ antiserum and $0.2 \mathrm{ml}$ carrier ferritin solution containing approximately $500 \mu \mathrm{g}$ ferritin. The mixture was then incubated for 1 hour at $37^{\circ} \mathrm{C}$. The ferritin-antiferritin complex, which appeared as a visible precipitate, was washed three times with distilled water after centrifugation at $1,500 \times g$ for $10 \mathrm{~min}$ utes. The $\mathrm{Fe}^{50}$ activity of the precipitate provided a measure of the $\mathrm{Fe}^{58}$-labeled ferritin present. In this method carrier ferritin was added to the solution for two reasons. First, precipitation could be verified by estimating the iron in the deposit using the thioglycollic acid method after wet digestion (17), and second the measurement of minute amounts of labeled ferritin was facilitated. The specificity of the antiserum was confirmed by the demonstration that no activity was precipitated on incubation with either rat hemoglobin or rat transferrin labeled with $\mathrm{Fe}^{50}$. The purpose of the EDTA was to prevent the attachment of $\mathrm{Fe}^{58}$ to carrier ferritin or to unlabeled mucosal ferritin. It was shown that if the chelate were present in a solution of $\mathrm{Fe}^{50} \mathrm{Cl}_{3}$ before adding ferritin, less than $0.2 \%$ of the label was precipitated with the ferritin-antiferritin complex. Mucosal supernatant solutions prepared with EDTA consisted of two fractions, the first precipitable with either perchloric acid or the ferritin antiserum and the second identifiable as EDTA-iron. This indicated that the chelate had taken up all nonferritin activity. Furthermore, the fact that only minimal ferritin labeling was observed under certain circumstances, e.g., in iron deficiency, provided added evidence to suggest that the approach was a valid one. Finally, it was necessary to establish that EDTA did not remove activity from physiologically labeled ferritin. This was done by incubating a solution of ferritin, prepared from rat livers after the intravenous injection of $5 \mu \mathrm{g} \mathrm{Fe}^{5 \theta}$-citrate, with $0.1 \mathrm{M}$ EDTA ( $\mathrm{pH} \mathrm{7.0)}$ for 1 hour.
On adding the antiserum $94 \%$ of the activity was recovered in the deposit.

A development of the agar gel diffusion plate technique (18) was also used to demonstrate the presence of radioactive ferritin in gut extracts. The antiserum was placed in the central well and gut extract in two of the peripheral wells, the remaining wells containing a solution of radioactive horse spleen ferritin. After the precipitation bands had formed, the gel was washed for 3 days with frequent changes of distilled water and then allowed to dry. A radioautograph of the paper-thin sheet so formed was then prepared.

Factors affecting ferritin recoveries. Experiments were done to find out to what extent washing of the gut affected the subsequent recovery of ferritin. Ten-cm lengths of duodenum taken from two animals 30 minutes after administration of $10 \mu \mathrm{g}$ labeled iron were divided longitudinally in half, the halves being weighed. One half of each duodenum was then washed as before, after which the labeled ferritin content was determined. The remaining halves were not washed, but were homogenized directly in 0.1 M EDTA. The labeled ferritin content of the unwashed portions was 20 to $25 \%$ higher than that of equivalent weights of washed intestine, indicating a significant loss of the ferritin-containing cells during the washing procedure. However, no attempt was made in subsequent experiments to correct for this loss.

In previous studies of iron absorption different centrifugation procedures have been used $(6,7)$. It was therefore of importance to establish the extent to which the speed of centrifugation influenced the recoveries of labeled ferritin in gut supernatant solutions. Approximately $500 \mu \mathrm{g}$ carrier horse spleen ferritin was added to each of several samples of heated supernatant solution, obtained from three rats that had been given $10 \mu \mathrm{g}$ radioiron 30 minutes previously. Half the samples were spun at $9,000 \times g$ for 20 minutes and half at $105,000 \times g$ for 60 minutes. Treatment of the supernatant solution with antiserum revealed that the labeled ferritin content of the three samples spun at high speed was between 50 and $59 \%$ lower than after low speed centrifugation. Further confirmation of the fact that ferritin iron can be precipitated by high speed centrifugation was obtained by analyzing chemically the iron content of the precipitate obtained after spinning a solution of pure horse spleen ferritin at $105,000 \times g$ for 60 minutes. Eighty per cent of the iron was found to be in the precipitate.

Other chemical methods. Ammonium sulfate precipitation was carried out by adding sufficient saturated ammonium sulfate solution, adjusted to $\mathrm{pH} 7.5$ in some experiments, to produce a final concentration of $80 \%$. Perchloric acid precipitation was achieved by adding $10 \%$ perchloric acid solution in a proportion of $1: 5$. When starch gel electrophoresis was employed, the method of Smithies (19) was followed, using $0.074 \mathrm{M}$ Tris buffer pH 9.5 (20). Column chromatography using DEAE cellulose ${ }^{2}$ and Sephadex $^{3}$ was also employed. Both

\footnotetext{
2 Whatman, obtained from W. \& R. Balston, Ltd. Maidstone, England.

3 Obtained from Pharmacia, Uppsala, Sweden.
} 


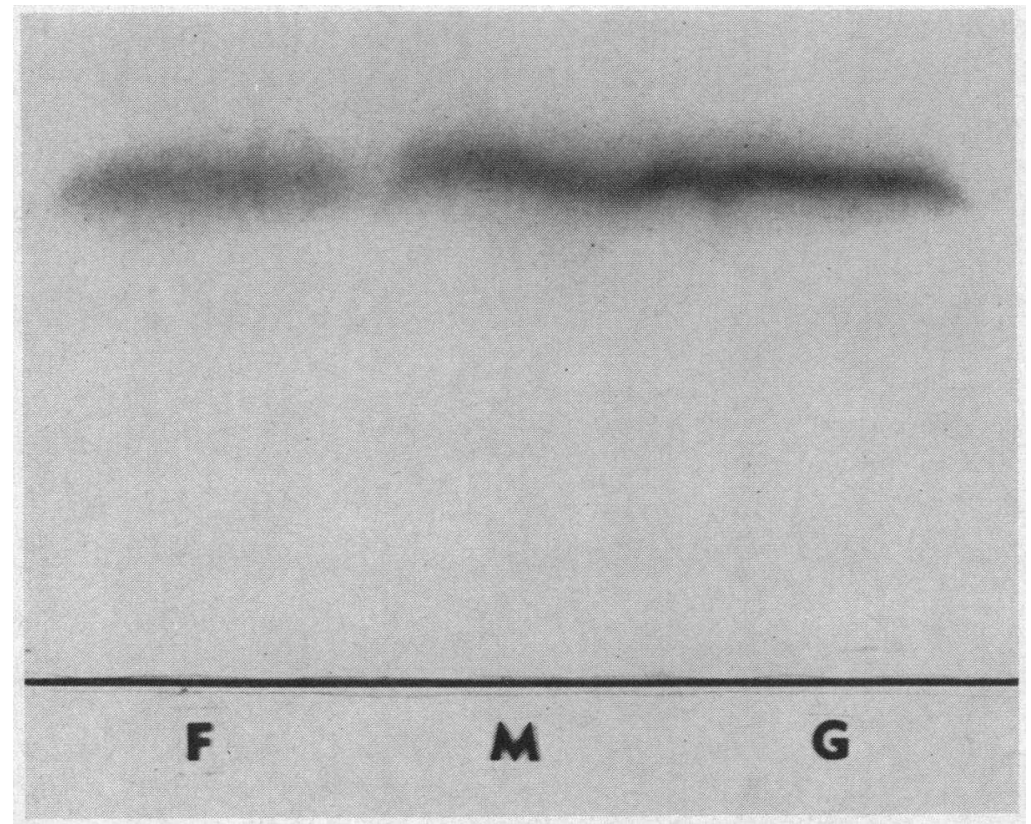

Fig. 1. RADIOAUtOGRAPH OF STARCH GEL ELECTROPHORESIS. F=horse spleen ferritin; $G=$ mucosal heat supernate; $M=a$ mixture of the two. (Although ferritin normally exhibits 3 or 4 discrete bands on starch gel electrophoresis, over $90 \%$ of the ferritin is located in one of them. Only this band is visible in the present radioautograph.)

stepwise and gradient elution from DEAE cellulose columns was used. With stepwise elution a $10-\times 1-\mathrm{cm}$ column was prepared in which the buffer was $\mathrm{M} / 150$ phosphate ( $\mathrm{pH} 8.0$ ). This was changed to $0.06 \mathrm{M} \mathrm{NaCl}$ dissolved in the starting buffer in order to elute transferrin and ferric EDTA, and then to $1.0 \mathrm{M} \mathrm{NaCl}$ in the same buffer, which eluted ferritin. A $30-\times 1.25-\mathrm{cm}$ column was prepared for gradient elution with the same starting buffer, while $1.0 \mathrm{M} \mathrm{NaCl}$, dissolved in this buffer, was used as the limiting buffer. Sephadex (G75 and G200) was prepared with $\mathrm{M} / 150$ phosphate buffer ( $\mathrm{pH} 8.0$ ) or with $0.9 \% \mathrm{NaCl}$ solution. Serum iron concentrations were estimated by a modification of the method of Bothwell and Mallett (21) in which sulfonated bathophenanthroline was used as the color reagent, and unsaturated iron-binding capacities by the method of Bothwell, Jacobs, and Kamener (22).

\section{Results}

Demonstration of radioactive ferritin in duodenal homogenate after administration of $1 \mu \mathrm{g}$ iron

Chromatography on Sephadex G200 of heated supernatant solution from the upper $10 \mathrm{~cm}$ of intestine of a rat given $1 \mu \mathrm{g}$ labeled iron 1 hour previously resulted in the appearance of a peak of activity corresponding to that obtained with purified horse spleen ferritin. A further sample of supernatant solution was subjected to starch gel electrophoresis, together with $a$ ) $\mathrm{Fe}^{\mathrm{so}}$-labeled horse spleen ferritin, and $b$ ) a mixture of the supernatant solution and labeled ferritin. A radioautograph of the gel showed that the bands of radioactivity were all in the same position (Figure 1). In a previously reported experiment (1) the supernatant solution was studied using the geldiffusion technique. No lines of precipitation could be seen opposite the wells containing the mucosal extract. However, a radioautograph prepared from the gel-diffusion plate showed bands of radioactivity in this position that coalesced with the bands opposite the ferritin wells (Figure 2).

The validity of these observations was tested in a further experiment in which $10 \mu \mathrm{g} \mathrm{Fe}^{59}$ was introduced into the lumens of guts that had been removed from three rats 24 hours previously and stored at $4^{\circ} \mathrm{C}$. After incubation at $37^{\circ} \mathrm{C}$ for 30 minutes, the guts were subjected to the usual procedures. Although $28 \%, 7 \%$, and $35 \%$ of the radioactivity was present in the washed guts, only $0.1 \%, 0.0 \%$, and $0.03 \%$, respectively, of this activity was attached to ferritin. These results indicated that the incorporation of $\mathrm{Fe}^{58}$ into ferritin demonstrated in the previous studies represented an active metabolic process. 
Proportion of mucosal radioactivity identifiable as ferritin

The distribution of radioactivity in the proximal $10 \mathrm{~cm}$ of intestines was studied at various times after the administration of $10 \mu \mathrm{g}$ labeled iron. Activity precipitable with the ferritin antiserum rose from a mean of $31 \%$ at 10 minutes to $75 \%$ at 60 minutes (Figure 3 ). During this period there was little change in the total mucosal activity, the increase in labeled ferritin being accompanied by a corresponding diminution in the nonferritin component. At 4 hours the pattern resembled the 1-hour distribution, the mean percentage identifiable as ferritin being $78 \%$. However, by 24 hours there was little residual radioactivity in the washed intestine. Essentially similar results were previously reported when the absorption of $100 \mu \mathrm{g}$ iron was studied (1).

The pattern of mucosal radioiron distribution after the administration of much larger amounts of iron was then studied. Two groups of ten rats were given $100 \mu \mathrm{g}$ and $10,000 \mu \mathrm{g}$ of iron, respectively, and killed after 5 hours, labeled ferritin in the whole small intestine being determined. The mean percentages of mucosal activity precipitable as ferritin were $45 \%(\mathrm{SE} \pm 4.7)$ with the $100-\mu \mathrm{g}$ dose and $12 \%(\mathrm{SE} \pm 1.3)$ with 10,000 $\mu \mathrm{g}$.

Mucosal uptake of radioactivity and the fraction precipitable as ferritin were then characterized in different anatomical regions of the small intestines of 7 rats, 7 hours after giving $10 \mu \mathrm{g}$ iron. Mean uptakes were $9.3 \%$ in the first $10 \mathrm{~cm}$, $4.1 \%$ in the proximal $25 \%$ of the remainder, and $3.0 \%$ in the rest of the small intestine. Respectively, $63 \%, 66 \%$, and $37 \%$ of this activity was attached to ferritin. Thus $57 \%$ of the total mucosal uptake 7 hours after ingestion was present in the first $10 \mathrm{~cm}$ of small intestine.

Fate of labeled mucosal ferritin. An attempt was made to determine whether iron incorporated into ferritin within mucosal cells can subsequently enter the plasma. Ten $\mu \mathrm{g}$ iron as $\mathrm{Fe}^{59} \mathrm{Cl}_{3}$ was administered to 25 rats, 13 animals being killed after 4 hours and the remainder after 24 hours. The mean proportion of the administered dose present in the carcasses at 4 hours was $23.9 \%$ $(\mathrm{SE} \pm 5.6)$ compared with $39.1 \%(\mathrm{SE} \pm 5.6)$ at 24 hours. The mean percentage present in the washed small intestine at 4 hours was $8.5 \%$ $(\mathrm{SE} \pm 1.0)$, and of this $69 \%(\mathrm{SE} \pm 5.2)$ was ferritin. These results, although inconclusive $(p<0.1)$, suggest that labeled iron within the mucosa 4 hours after administration may subsequently pass into the body. The fact that the sum of the mean mucosal and carcass activity at 4 hours was less than the mean activity present in the carcass at 24 hours may be partly ascribed to the loss of mucosal cells during the initial washing procedures (see Methods). When a larger dose of iron was given $(100 \mu \mathrm{g})$, the results were somewhat different. A mean of $28.8 \%$ ( $\mathrm{SE} \pm$

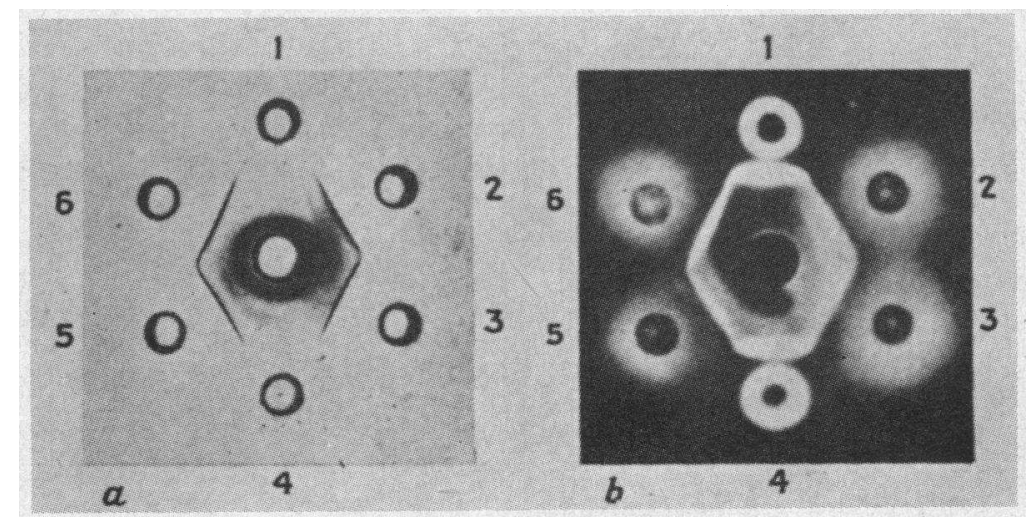

Fig. 2. Agar gei diffusion plate. Wells 1 and 4 contain duodenal homogenate; wells $2,3,5$, and 6 contain ferritin. Although no lines of precipitation can be seen opposite the wells containing the heat supernatant solution from the duodenal homogenate (a), the radioautograph (b) reveals bands of radioactivity coalescing with the bands opposite the ferritin wells. (Reprinted by courtesy of the Editor, Lancet.) 


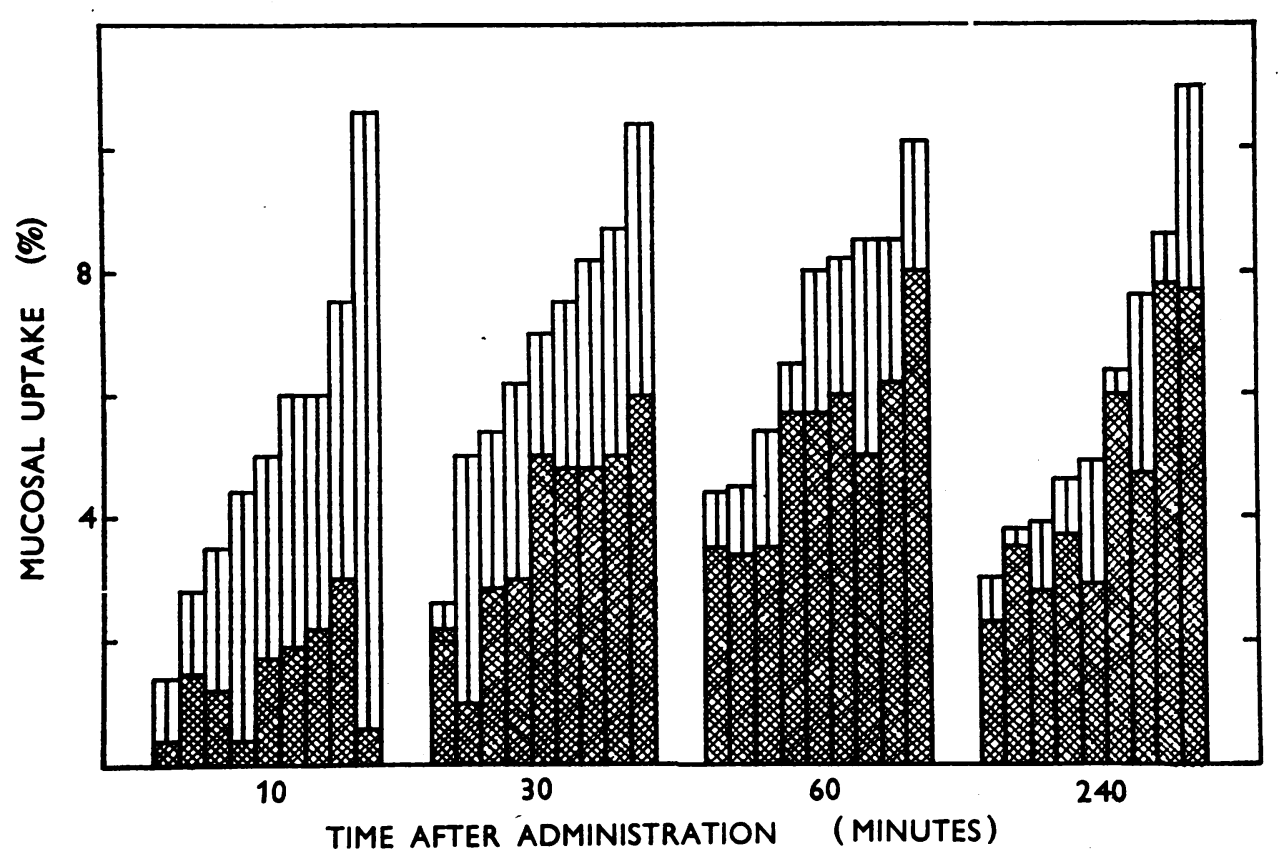

Fig. 3. LABELED FERRITIN (HATCHED) AND NONFERRITIN ACTIVITY IN THE UPPER SMALL INTESTINE AT VARIOUS INTERVALS AFTER ADMINISTRATION OF $10 \mu \mathrm{G} \mathrm{FE}^{50}$.

4.3) of the administered dose was in the carcasses of nine animals at 4 hours, a mean of $6.3 \%$ ( $\mathrm{SE} \pm$ 1.0 ) being in the washed intestines; $74 \%$ ( $\mathrm{SE} \pm$ 6.0) of intestinal activity was precipitable as ferritin. However, after 24 hours only $30.2 \%$ (SE \pm 5.0 ) was in the remaining nine carcasses.

In an attempt to demonstrate this incomplete transfer of mucosal activity into the animal more convincingly, the absorption of $10 \mu \mathrm{g}$ iron was studied in eight animals overloaded with iron by intramuscular injection (see Methods), as previously reported (1). The results, summarized in Table I, indicate that nearly all the activity present in the mucosa at 2 hours had disappeared by 24 hours, even though carcass activity had hardly altered. The total absorptions were considerably reduced when compared with a control group of four normal rats (mean 19.6\%). In further studies it became apparent that marked depression in iron absorption only occurred in ironoverloaded animals that had received parenteral iron up until 24 hours before study. For example, in one experiment absorption was studied in ten animals that had received their last injection 7 days previously. The mean absorption was $8.3 \%(\mathrm{SE} \pm 1.7)$ as compared with $12.6 \%$ $(\mathrm{SE} \pm 1.3)$ in a control group of ten animals.
Since it seemed possible that the low absorption shortly after the last injection of iron-sorbitol-citrate might be due to high levels of iron in the circulation, the serum iron concentrations were determined in a parallel experiment. At 2 and 4 hours after the final intramuscular dose, figures ranging from 590 to $630 \mu \mathrm{g}$ per $100 \mathrm{ml}$ were observed. At 9 hours the concentrations were 370 and $440 \mu \mathrm{g}$ per $100 \mathrm{ml}$, and by 14 hours the levels had fallen to 220 and $215 \mu \mathrm{g}$ per $100 \mathrm{ml}$. Twenty-

TABLE I

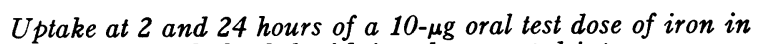
rats previously loaded with iron by repeated intramuscular injections

\begin{tabular}{|c|c|c|c|}
\hline $\begin{array}{l}\text { Time } \\
\text { after } \\
\text { admin- } \\
\text { istra- } \\
\text { tion }\end{array}$ & $\begin{array}{l}\% \text { dose in } \\
\text { washed in- } \\
\text { testinal } \\
\text { mucosa }\end{array}$ & $\begin{array}{c}\% \text { dose in } \\
\text { mucosal } \\
\text { ferritin }\end{array}$ & $\begin{array}{l}\% \text { dose in } \\
\text { rest of } \\
\text { animal }\end{array}$ \\
\hline \multicolumn{4}{|l|}{ hrs } \\
\hline \multirow[t]{4}{*}{2} & 26 & 15 & 1.8 \\
\hline & 24 & 17 & 2.6 \\
\hline & 52 & 16 & 3.0 \\
\hline & $\begin{array}{c}37 \\
\text { (Mean 35) }\end{array}$ & $\stackrel{18}{(\text { Mean 16.5) }}$ & $\begin{array}{c}5.7 \\
\text { (Mean 3.3) }\end{array}$ \\
\hline \multirow[t]{4}{*}{24} & 1.9 & 1.3 & 3.2 \\
\hline & 4.1 & 1.5 & 4.1 \\
\hline & 2.8 & 1.5 & 5.7 \\
\hline & 2.7 & $\begin{array}{c}1.2 \\
(M e a n ~ 14)\end{array}$ & $\begin{array}{c}5.9 \\
(\text { Mean 4.7) }\end{array}$ \\
\hline
\end{tabular}


TABLE II

Comparison between the absorptive patterns in normal and iron-deficient rats 4 hours after administration

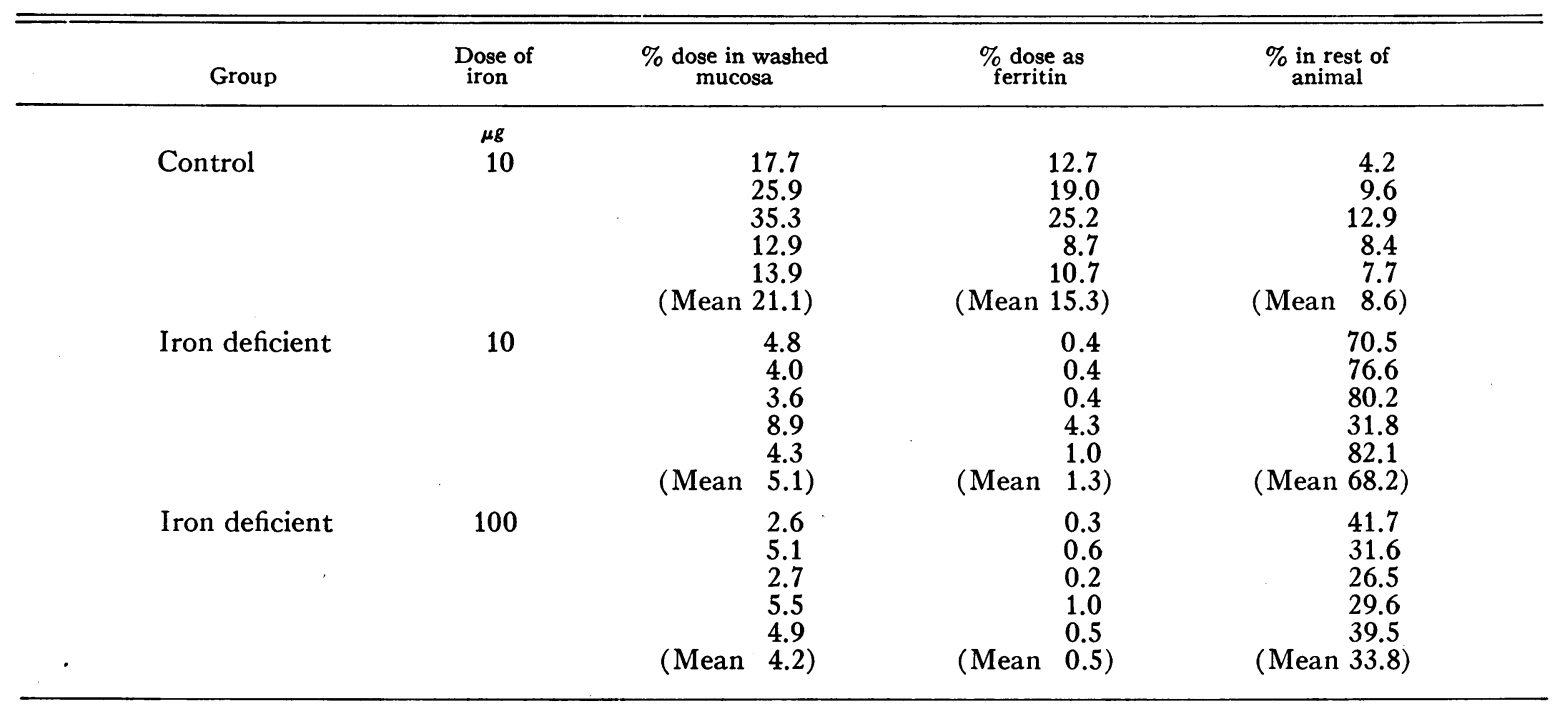

four hours after the last injection concentrations of 232,165 , and $157 \mu \mathrm{g}$ per $100 \mathrm{ml}$ were found.

The absorptive process was then studied in iron-deficient animals. The results, summarized in Table II, show that although absorption was considerably enhanced compared with the control group, very little activity was present in the mucosas as ferritin even when $100 \mu \mathrm{g}$ iron was administered. A similar absorptive pattern was observed in ten animals after venesection, as previously reported (1).

\section{Characterization of nonferritin radioiron in mu- cosal supernatant solution}

Several experiments were carried out in an attempt to elucidate the nature of radioactivity present in mucosal supernatant solution that was not

TABLE III

Distribution of supernatant radioactivity in pooled mucosas (prepared with EDTA) from four groups of nine rats at various times after administering $10 \mu \mathrm{g}$ oral iron

\begin{tabular}{cccc}
\hline \hline $\begin{array}{c}\text { Time } \\
\text { after ad- } \\
\text { ministra- } \\
\text { tion }\end{array}$ & $\begin{array}{c}\text { \% pre- } \\
\text { cipitated } \\
\text { by per- } \\
\text { chloric } \\
\text { acid }\end{array}$ & $\begin{array}{c}\% \text { pre- } \\
\text { cipitated } \\
\text { by anti- } \\
\text { ferritin } \\
\text { serum }\end{array}$ & $\begin{array}{c}\text { \% di- } \\
\text { alyzable }\end{array}$ \\
\hline $\min$ & & & \\
10 & 30 & 32 & 66 \\
30 & 50 & 48 & 50 \\
60 & 62 & 68 & 31 \\
240 & 80 & 76 & 12 \\
\hline
\end{tabular}

attached to ferritin. In extracts prepared with EDTA, a close correspondence was found between the percentages of radioactivity precipitated by perchloric acid and by the antiferritin serum, and the sum of either of these and the percentage that was dialyzable accounted for between $88 \%$ and $100 \%$ of the activity in each case (Table III). On chromatography using a DEAE cellulose column with stepwise elution, two peaks of radioactivity were obtained, the first with $0.06 \mathrm{M}$ $\mathrm{NaCl}$ and the second with $1.0 \mathrm{M} \mathrm{NaCl}$. The activity in the first fraction was found to be dialyzable, and no precipitation with the ferritin antiserum occurred. In contrast, the second fraction was not dialyzable, and $90 \%$ of the activity was precipitated as ferritin. In mucosal extracts from animals killed at 10 minutes, 30 minutes, $60 \mathrm{~min}$ utes, and 4 hours, $47 \%, 33 \%, 15 \%$, and $8 \%$, respectively, were in the first fraction and $29 \%$, $39 \%, 52 \%$, and $60 \%$ in the second. Investigation of the dialyzable fraction by paper electrophoresis with a barbital buffer $(\mathrm{pH} 8.6)$ and paper chromatography with a phenol solvent established that this activity was bound to EDTA. These observations may have relevance to the previous reported finding by Brown and Rother $(6,7)$ of a dialyzable fraction in mucosal supernatant solutions that appeared to consist of complexes of iron with glycine and serine. In the present study the observations were confirmed, 
but only when the gut was initially washed with the chelate Versene Fe-3 Specific, as described by these workers. Further experiments revealed that the behavior of this fraction of radioiron on chromatography [ethanol: water: cyclohexane (6)] and on paper electrophoresis [acetate buffer, $\mathrm{pH} 4.6$ (6) ] was identical to that of a complex of iron and Versene $\mathrm{Fe}-3$ Specific.

When mucosal supernatant solution from animals killed at 10 minutes was prepared without chelate, none of the activity was dialyzable unless the $\mathrm{pH}$ was brought below 5 . In 10 further experiments a mean of $36 \%$ of the supernatant activity was precipitable with the ferritin antiserum, whereas $42 \%$ was precipitable with perchloric acid. Comparable figures with ammonium sulfate were $57 \%$ at $\mathrm{pH} 4.6$ and $92 \%$ at $\mathrm{pH} 7.5$. This suggested that some of the nonferritin activity might be protein-bound. However, on chromatography using Sephadex G200 only one peak of activity ( $90 \%$ precipitable with the ferritin antiserum) was obtained, the rest of the activity remaining on the column. With Sephadex G75 all the activity emerged in a single peak. On DEAE cellulose chromatography 1 to $9 \%$ appeared in the same position as that of $\mathrm{Fe}^{59}$-labeled transferrin in rat plasma; however, 40 to $64 \%$ was not eluted from the column. On paper elec- trophoresis using a barbital buffer $\mathrm{pH} \mathrm{8.5,} \mathrm{a} \mathrm{band}$ of radioactivity was demonstrable in the same position as transferrin. The significance of the presence of labeled transferrin was not clear, however, as it seemed possible that the nonferritin mucosal fraction might be in a form that could be taken up by contaminating plasma present in gut extract. Some support for this was obtained in a further experiment in which unlabeled plasma was added to the supernatant solution; this raised the percentage eluted in the transferrin fraction from 6 to $24 \%$ (Figure 4 ).

The fact that labeled nonferritin iron in gut extract was readily available for combination with EDTA and transferrin raised the possibility that it was present as a simple inorganic compound. Further experiments to test this thesis were done. The addition of alpha-alpha-dipyridyl to a sample of mucosal supernatant solution did not render the radioactivity dialyzable. This suggested that free iron, if present, was not in the ferrous form. However, when labeled ferric chloride was added to "cold" mucosal supernatant solution, its behavior resembled that of the nonferritin fraction fairly closely. Only $15 \%$ of the activity was dialyzable, whereas more than $90 \%$ was precipitated by ammonium sulfate $\mathrm{pH} 7.5$. Perchloric acid did not precipitate any of the radioactivity. Ap-

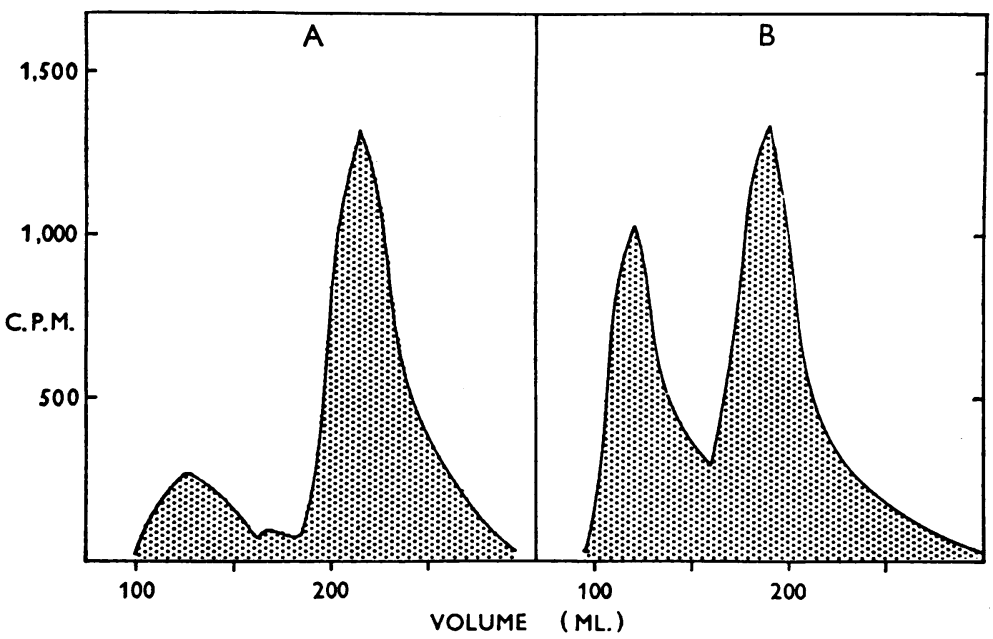

Fig. 4. DEAE cellulose Chromatography : A. MUCOSAl supernate; B. MIXTURE OF SUPERNATE WITH UNLABELED PLASMA. Although some activity was eluted in the transferrin position when supernate only was chromatographed, the amount was considerably increased by the addition of plasma (24\% of the activity placed on the column compared with $6 \%$ ). The second peak consisted of labeled ferritin in each instance. 
TABLE IV

Effect of the timing of three intravenous injections of $50 \mu \mathrm{g}$ iron upon the absorption of an oral test dose

\begin{tabular}{|c|c|}
\hline $\begin{array}{l}\text { Timing of intra- } \\
\text { venous ferric am- } \\
\text { monium citrate: } \\
\text { hours before }(-) \\
\text { and after }(+) \text { oral dose }\end{array}$ & $\begin{array}{c}\text { Mean absorp- } \\
\text { tion ( }( \pm \mathrm{SE}) \\
(\% \text { administered } \\
\text { dose of } 10 \mu \mathrm{g})\end{array}$ \\
\hline $\begin{array}{r}-48,-43,-38 \\
-18,-13,-8 \\
-6,-1,+3 \\
0,+5,+10 \\
0, *+5,+10\end{array}$ & $\begin{array}{l}28.3 \pm 4.2 \\
12.0 \pm 1.6 \\
40.6 \pm 3.8 \\
54.1 \pm 5.8 \\
54.2 \pm 5.0\end{array}$ \\
\hline
\end{tabular}

* A control group given saline injections instead of ferric ammonium citrate.

proximately $50 \%$ emerged in a single peak from a Sephadex G75 column, although tracer alone remained at the top of the column.

Factors influencing mucosal behavior. Since results obtained in an earlier experiment suggested that the parenteral administration of iron affected mucosal behavior 24 hours later, a study was carried out to define this effect in more detail. Three intravenous injections of $50 \mu \mathrm{g}$ iron as ferric ammonium citrate were given at intervals of 5 hours. ${ }^{4}$ The iron was dissolved in $1 \mathrm{ml}$ $0.9 \% \mathrm{NaCl}$ solution and administered via the tail veins. The injections were given at different times before and after the oral administration of $10 \mu \mathrm{g}$ labeled iron (Table IV). A marked depression of absorption was observed in the group of animals given intravenous iron 18,13 , and 8 hours before the oral dose, with lesser effects in the earlier and later groups. Iron given intravenously immediately before the oral dose had no effect, as previously reported by Wheby and Jones (23). In a parallel experiment, labeled ferric ammonium citrate was given intravenously to find out what proportion localized in the gut. Between 6.5 and $7.9 \%$ was present in the gastrointestinal tract 18 hours later, with 1.4 to $1.8 \%$ in the upper $10 \mathrm{~cm}$ of small intestine. Perfusion of the whole gut showed that only negligible amounts of radioactivity were present in the lumens.

In a second experiment an attempt was made to modify the absorption of iron by manipulating the amount of iron taken in the diet, as described

4 Preliminary studies established that the percentage saturation of circulating transferrin remained over $80 \%$ for the first 12 hours. By 15 hours it had returned to $34 \%$. In control animals given saline injections percentage saturations varied between 12 and $44 \%$. by Bannerman, O'Brien, and Witts (24). Forty matched rats receiving their normal diet were given, in addition, $1,000 \mu \mathrm{g}$ iron as ferric chloride twice daily for 5 days by esophageal catheter. They were then put on an iron-free diet, and the absorption of $10 \mu \mathrm{g}$ labeled iron was studied at various times after the changeover. The results are shown in Figure 5, together with those from a second similar experiment. Serum iron levels at various stages were also estimated. A progressive increase in absorption up to 60 hours after the withdrawal of iron from the diet was observed. Since it seemed possible that the low absorption observed at an early stage might be due to dilution of the isotopic label with residual "cold" iron, either within the gut lumen or in the absorbing cells, a further experiment was carried out. Ten rats were given a single oral dose of $1,000 \mu \mathrm{g}$ "cold" iron 24 hours before a labeled dose of $10 \mu \mathrm{g}$, and another ten animals, 12 hours before. The control group was given water. Mean absorptions in the three groups were $32.0 \%$ ( $\mathrm{SE} \pm 4.9$ ), 33.0\% ( $\mathrm{SE} \pm 4.1$ ), and $30.2 \%$ ( $\mathrm{SE}$ $\pm 3.5)$, respectively.

\section{Discussion}

The observations reported in this paper, together with those in a previous communication (1), indicate that iron may be incorporated into ferritin during the process of absorption of small amounts from the gut in rats. The process appears to be dependent upon metabolic activity, since less than $0.1 \%$ of the labeled iron taken up by a segment of dead intestine was attached to ferritin. Evidence was also obtained which suggested that the labeled iron preferentially entered ferritin molecules with a relatively low iron content. Ultracentrifugation of a solution of ferritin led to the precipitation of $80 \%$ of the ferritin iron. However, when the supernatant solution from mucosal homogenate was subjected to the same procedure, only 50 to $60 \%$ of the labeled ferritin iron was spun down. Mazur, Litt, and Shorr (25) have shown that centrifugation of a solution of ferritin results in its separation into iron-rich and iron-poor fractions, and the current observations therefore suggest that a greater proportion of mucosal $\mathrm{Fe}^{59}$ is attached to iron-poor ferritin molecules. Similar observations 
have been reported with regard to hepatic ferritin (16).

When the proportion of mucosal radioactivity attached to ferritin was examined under various circumstances, some insight was gained into its function in the absorptive process. During the first hour after administration there was a progressive rise in the percentage bound to ferritin, with a corresponding fall in the nonferritin fraction (Figure 3). Both the present study and previous investigations $(10,26,27)$ have established that iron moves rapidly across the mucosa at an early stage and much more slowly thereafter. Since most of the mucosal activity is attached to ferritin in the later phases, it seems probable that ferritin is not directly concerned with the transfer of iron across the cell. Results in iron-deficient animals support this interpretation, since a very rapid transfer of large percentages of the administered dose was observed although little labeled ferritin was present in the mucosa (Table II). In a previous study, Brown and Rother (7) noted that most of the radioactivity in the supernate from mucosal homogenate was not bound to protein when absorption was enhanced. In normal animals they found a build-up in a labeled fraction, precipitable with perchloric acid, during the first hour, and although these workers did not believe that the fraction represented ferritin, results in the current study indicated a close correlation between the perchloric acid and ferritin fractions (Table III).

The ultimate fate of iron sequestered within mucosal cells appears to depend on several factors. Using small doses of iron, Wheby and Crosby (10) have produced evidence that some of this iron may feed gradually into the body. Similar findings were obtained in the current study. However, it was not possible to show the late absorption of mucosal activity when larger doses were given, or when small doses were given to animals that had recently received parenteral iron. The results in this last experiment, which have been previously reported (1), were particularly striking. Two hours after the administration of radioiron, a mean of $35 \%$ of the administered activity was in the mucosas and $3.3 \%$ in the remainder of the carcasses. By 24 hours mucosal radioactivity had dropped to negligible levels, whereas the mean activity in the carcasses was only $4.7 \%$. Mucosal iron must therefore have been lost into the lumen of the

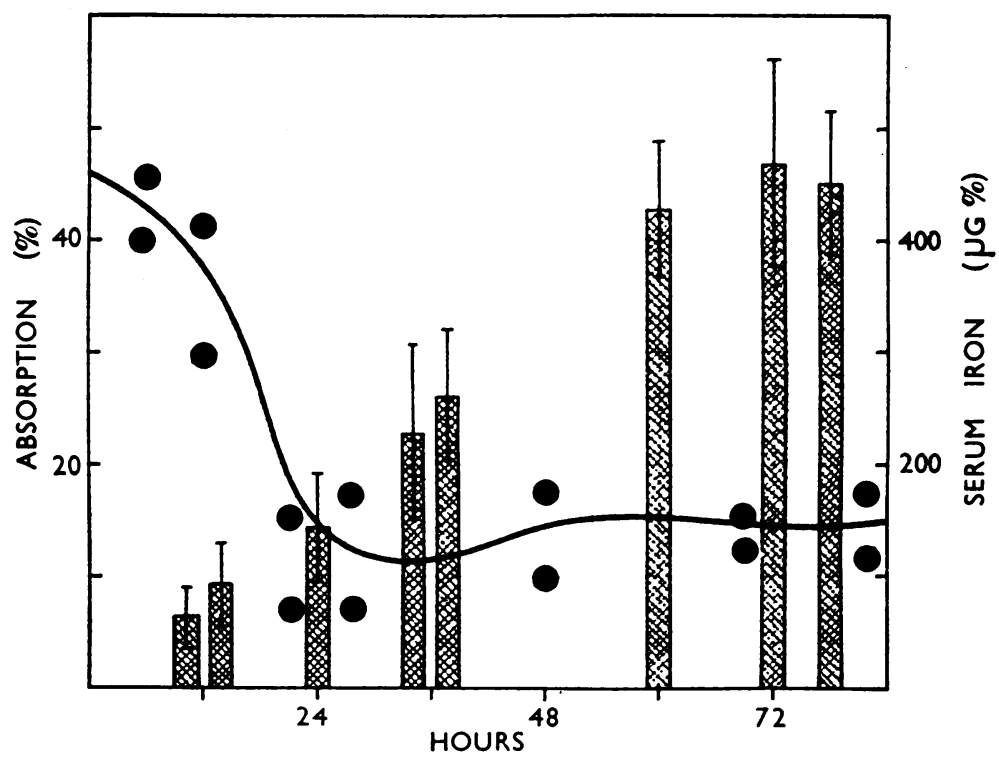

Fig. 5. Absorption of $10 \mu \mathrm{G} \mathrm{FE}^{\mathrm{DO}}$ at various times AFTER SWitching FROM A HIGH TO A LOW IRON DIET (HATCHED COLUMNS). Mean values ( $\pm \mathrm{SE}$ ) for each group of 10 rats are given. Serum iron concentrations obtained in a parallel experiment are also plotted (black circles). A progressive increase in mean absorptions between 24 and 60 hours is demonstrated. 
gut. Theoretically this could occur either by extrusion of ferritin from the mucosa or via exfoliation of the intestinal cells. Conrad and Crosby (9) have published observations strongly supporting the second possibility. Using radioautographs of rat intestinal mucosa at various intervals after the oral administration of labeled iron, these workers have demonstrated both the sequestration of $\mathrm{Fe}^{59}$ within the mucosal cells and the progress of the labeled cells towards the tips of the villi. As a result of their studies, these workers envisaged a mucosal mechanism for the control of iron absorption in which iron taken up from the intestinal lumen into the absorbing cells in excess of body requirements is trapped within the mucosa and discarded when these cells exfoliate. They postulated that the sequestered iron is in the form of ferritin, and the present study provides evidence in support of this suggestion. Although this mechanism appears to function well when small amounts of iron are presented to the mucosa, the percentage of mucosal activity precipitable as ferritin is much lower with large doses.

The nature of the nonferritin activity in mucosal supernatant solution was also investigated in the present study. High concentrations of activity appeared in this fraction shortly after the administration of labeled iron, and then declined rapidly over the next 2 hours. These findings indicate that it was probably concerned in the initial rapid phase of iron absorption. Previous reports by Brown and Rother $(6,7)$ have suggested that a proportion of the iron present in this fraction is attached to the amino acids glycine and serine. However, the results of the present studies indicate that the findings obtained by these workers were due to the complexing of iron with the chelate Versene Fe-3 Specific, which had been used in the initial washing of the mucosa.

Further investigation was not successful in positively establishing the nature of the bulk of the nonferritin activity. Although small and variable percentages often appeared to be attached to transferrin, the significance of this finding is open to question, since evidence was obtained suggesting that iron present in some other form might attach to the transferrin of contaminating plasma during the initial separation procedures (Figure 4). The nature of the remaining non- ferritin fraction was not elucidated, but certain of its characteristics were defined. The iron was in a form that was only dialyzable if EDTA or Versene $\mathrm{Fe}-3$ Specific had been present during the preparation of the homogenate. It was largely precipitable with ammonium sulfate $\mathrm{pH} 7.5$, but not with perchloric acid or ammonium sulfate $\mathrm{pH}$ 4.6. Upon electrophoresis, whether paper or starch gel, it did not migrate from the point of application. Furthermore, upon chromatography of mucosal supernatant solution using either Sephadex G 200 or DEAE cellulose, this fraction remained on the column. It could be chelated by EDTA ( $\mathrm{pH} 7.0$ ) in a concentration of $0.01 \mathrm{M}$, and some at least could be taken up by transferrin and also by ferritin. However, the specificity of these properties seemed uncertain, since very similar findings were observed when labeled ferric chloride was added to "cold" gut homogenate.

Finally, an attempt was made to discover how mucosal cell behavior with regard to the handling of iron is regulated. In general, when body iron stores are depleted or when erythropoiesis is stimulated acutely, more iron passes through the mucosa into the plasma (2). On the other hand, the present findings indicate that a major portion of the iron taken up from the lumen is trapped in mucosal cells when the body iron content is high, and this is specially so when a recent parenteral injection has been given. This suggests that mucosal cell function may be determined, at least in part, by the iron content of absorbing cells. However, maneuvers that might be expected to modify the iron content of mucosal cells, such as raising the serum iron level (23), or administering "blocking" doses of iron orally (28), have led to equivocal results. In the present study the effects of previous parenteral and oral iron administration were reinvestigated in several ways.

The administration of three intravenous doses of ferric ammonium citrate at 5-hour intervals had no immediate effect, but a depression in absorption was apparent 6 hours after the first injection and was marked at 18 hours (Table IV). By 48 hours absorption had risen again, although not yet to control levels. The present findings are in agreement with those reported by Conrad, Weintraub, and Crosby (29), who noted a depression in absorption in rats 24 hours after the 
administration of a single large injection of iron. These workers suggested that the behavior of mucosal cells is conditioned during their developmental period in the crypts of Lieberkühn. On this basis any manipulation of the cellular environment must be followed by a latent period during which "conditioned" cells move out into their functional position on the villi. The present results are compatible with this thesis, since the observed changes in absorption correlate well with the turnover rate of intestinal cells (30). Parallel studies indicated that the percentage saturation of circulating transferrin was maintained at high levels for the first 12 hours of the study. It is thus possible, though not proven, that the changes in mucosal behavior were related to this environmental factor.

In a final study, previous observations of Bannerman, O'Brien, and Witts (24) were confirmed. Stock rats were subjected to a high oral intake of iron for several days, and then an abrupt change was made to a diet with a very low iron content. Absorption increased progressively between 24 and 60 hours after the changeover, and it was shown that the initially low absorption could not be ascribed to dilution of the label with "cold" iron still present in the lumen or in functional mucosal cells. In a recent communication Pollack, Kauffman, and Crosby (31) reported similar findings in rats switched to a low iron diet from a normal intake. Although the differences were not statistically significant until the animals had been fed the new diet for 4 days, a steady rise in mean absorption after the changeover was also observed in this study. These workers showed that this increased absorption had not been triggered by the small net loss of iron on the low iron regime, and that neither the half-time of $\mathrm{Fe}^{59}$ in the plasma nor the serum iron level was different from the control group. In the light of these observations, the fall in serum iron concentration in the present study may not be causally related to the subsequent change in absorption, even though the timing of these events is suggestive (Figure 5). Nevertheless, the gradual increase in absorption over several days is compatible with the steady replacement of the absorbing mucosa by new cells "conditioned" during their development, in some way not yet established, by the altered iron content of the diet.

\section{Summary}

After administering radioactive ferric chloride in small amounts to rats, labeled ferritin was identified in homogenates of intestinal mucosa, as previously reported in a preliminary communication. During the first hour the percentage of mucosal activity attached to ferritin increased, whereas nonferritin activity declined proportionately. The nonferritin mucosal activity was not positively identified, but was present in a form that was not dialyzable; it could readily be taken up by EDTA, and also, in part at least, by ferritin and by plasma transferrin. No evidence was obtained to support the conclusion of other workers that the iron in this fraction is complexed with glycine and serine.

As observed by several previous workers, absorption occurred most actively shortly after the administration of radioiron. The fact that the concentration of nonferritin activity fell rapidly from initial high levels over the same period suggested that this fraction was concerned in the early active phase of absorption. In contrast, the activity incorporated into ferritin was temporarily stored within mucosal cells. Although suggestive evidence was obtained that some of this iron might eventually feed into the plasma, this did not occur under certain circumstances. For example, in animals recently given parenteral iron a large proportion of the activity taken up from the lumen was not absorbed, but was lost to the body with exfoliation of the mucosal cells. This deviation of iron into ferritin may therefore represent a mechanism for preventing excessive absorption from the gut. However, it was noteworthy that the percentage of mucosal activity formed into ferritin was reduced when large doses of iron were administered. This suggests that the mechanism is only effective when iron intake is within the physiological range.

Previous workers have concluded that mucosal cells are conditioned at an early stage of their development with regard to the handling of iron subsequently taken up from the lumen. Observations supporting this concept were made in the present study. After repeated intravenous injections of iron no immediate effect on absorption was detected, but a marked depression was observed 18 hours later. Mucosal behavior could 
also be altered by manipulating the dietary iron content. After 5 days on a high iron intake, during which high serum iron levels were observed, animals were switched to a diet containing very little iron, and within 24 hours the serum iron concentration returned to normal. Absorption was low at the time of the dietary change, but rose progressively over several days.

\section{References}

1. Charlton, R. W., P. Jacobs, J. D. Torrance, and T. H. Bothwell. The role of ferritin in iron absorption. Lancet 1963, 2, 762.

2. Bothwell, T. H., and C. A. Finch. Iron Metabolism. Boston, Little, Brown, 1962.

3. Granick, S. Protein apoferritin and ferritin in iron feeding and absorption. Science 1946, 103, 107.

4. Gabrio, B. W., and K. Salomon. Distribution of total ferritin in intestine and mesenteric lymph nodes of horses after iron feeding. Proc. Soc. exp. Biol. (N. Y.) 1950, 75, 124.

5. Heilmeyer, L. Ferritin in Iron in Clinical Medicine, R. O. Wallerstein and S. R. Mettier, Eds. Los Angeles, University of California Press, 1958, p. 24.

6. Brown, E. B., and M. L. Rother. Studies of the mechanism of iron absorption. I. Iron uptake by the normal rat. J. Lab. clin. Med. 1963, 62, 357.

7. Brown, E. B., and M. L. Rother. Studies of the mechanism of iron absorption. II. Influence of iron deficiency and other conditions on iron uptake by rats. J. Lab. clin. Med. 1963, 62, 804.

8. Beutler, E. Clinical Disorders of Iron Metabolism. New York, Grune \& Stratton, 1963, p. 35.

9. Conrad, M. E., Jr., and W. H. Crosby. Intestinal mucosal mechanisms controlling iron absorption. Blood 1963, 22, 406.

10. Wheby, M. S., and W. H. Crosby. The gastrointestinal tract and iron absorption. Blood 1963, 22, 416.

11. Crosby, W. H. Editorial review. The control of iron balance by the intestinal mucosa. Blood 1963, 22, 441.

12. Hartman, R. S., M. E. Conrad, Jr., R. E. Hartman, R. J. T. Joy, and W. H. Crosby. Ferritin-containing bodies in human small intestinal epithelium. Blood 1963, 22, 397.

13. Valber, L. S., K. B. Taylor, L. J. Witts, and W. C. Richards. The effect of iron deficiency on the stomach of the rat. Brit. J. Nutr. 1961, 15, 473.

14. Mazur, A., and E. Shorr. A quantitative immunochemical study of ferritin and its relation to the hepatic vasodepressor material. J. biol. Chem. 1950, 182, 607.
15. Proom, H. Preparation of precipitating sera for identification of animal species. J. Path. Bact. 1943, 55, 419.

16. Mazur, A., S. Green, and A. Carleton. Mechanism of plasma iron incorporation into hepatic ferritin. J. biol. Chem. 1960, 235, 595.

17. McCance, R. A., E. M. Widdowson, and L. R. B. Shackleton. The nutritive value of fruits, vegetables and nuts. Spec. Rep. Ser. med. Res. Coun. (Lond.) 1938, no. 213, 21.

18. Bodman, J. Agar gel starch block, starch gel and sponge rubber electrophoresis in Chromatographic and Electrophoretic Techniques, I. Smith, Ed. New York, Interscience, 1960, vol. 2, p. 119.

19. Smithies, O. Zone electrophoresis in starch gels: group variations in the serum proteins of normal human adults. Biochem. J. 1955, 61, 629.

20. Haut, A., G. R. Tudhope, G. E. Cartwright, and M. M. Wintrobe. The nonhemoglobin erythrocytic proteins, studied by electrophoresis on starch gel. J. clin. Invest. 1962, 41, 579.

21. Bothwell, T. H., and B. Mallett. The determination of iron in plasma or serum. Biochem. J. 1955, 59, 599.

22. Bothwell, T. H., P. Jacobs, and R. Kamener. The determination of the unsaturated iron-binding capacity of serum using radioactive iron. S. Afr. J. med. Sci. 1959, 24, 93.

23. Wheby, M. S., and L. G. Jones. Role of transferrin in iron absorption. J. clin. Invest. 1963, 42, 1007.

24. Bannerman, R. M., J. R. P. O'Brien, and L. J. Witts. Studies in iron metabolism. IV. Iron absorption in experimental iron deficiency. Blood 1962, 20, 532.

25. Mazur, A., I. Litt, and E. Shorr. Chemical properties of ferritin and their relation to its vasodepressor activity. J. biol. Chem. 1950, 187, 473.

26. Stewart, W. B., and S. R. Gambino. Kinetics of iron absorption in normal dogs. Amer. J. Physiol. 1961, 201, 67.

27. Hallberg, L., and L. Sölvell. Absorption of a single dose of iron in man. Acta med. scand. 1960, 168, (suppl. 358), 19.

28. Brown, E. B., Jr., R. Dubach, and C. V. Moore. Studies in iron transportation and metabolism. XI. Critical analysis of mucosal block by large doses of inorganic iron in human subjects. $\mathrm{J}$. Lab. clin. Med. 1958, 52, 335.

29. Conrad, M. E., L. R. Weintraub, and W. H. Crosby. The role of the intestine in iron kinetics. J. clin. Invest. 1964, 43, 963.

30. Messier, B., and C. P. Leblond. Cell proliferation and migration as revealed by radioautography after injection of thymidine- $\mathrm{H}^{3}$ into male rats and mice. Amer. J. Anat. 1960, 106, 247.

31. Pollack, S., R. M. Kauffman, and W. H. Crosby. Iron absorption: the effect of an iron-deficient diet. Science 1964, 144, 1015. 